\title{
Trends in Indices of Extreme Temperature and Precipitation in Iran over the Period 1960-2014
}

\author{
Mohammad Rahimi' ${ }^{1}$ Nooshin Mohammadian², Ameneh Rezei Vanashi' ${ }^{1}$, Kirien Whan ${ }^{3}$ \\ ${ }^{1}$ Department of Combat Desertification, Faculty of Desert Studies, Semnan University, Semnan, Iran \\ ${ }^{2}$ I.R. of Iran Meteorological Organization, Tehran, Iran \\ ${ }^{3}$ Royal Netherlands Meteorological Institute, De Bilt, The Netherlands \\ Email:mrahimi@semnan.ac.ir
}

How to cite this paper: Rahimi, M., Mohammadian, N., Rezei Vanashi, A. and Whan, K. (2018) Trends in Indices of Extreme Temperature and Precipitation in Iran over the Period 1960-2014. Open Journal of Ecology, 8, 396-415.

https://doi.org/10.4236/oje.2018.87024

Received: May 30, 2018

Accepted: July 27, 2018

Published: July 30, 2018

Copyright $\odot 2018$ by authors and Scientific Research Publishing Inc. This work is licensed under the Creative Commons Attribution International License (CC BY 4.0).

http://creativecommons.org/licenses/by/4.0/

cC) (7) Open Access

\begin{abstract}
Climate extremes can have many negative effects on different sectors. Globally, observations show significant changes in the characteristics of extreme events. We examined trends in extreme temperature and precipitation indices in Iran during the period 1960-2014. We present results from 33 quality controlled and homogenous synoptic stations (excluding stations with excessive missing data). For each station, we calculate 27 indices characterizing extreme temperature and precipitation. For all indices (including Rx5DAY, CWD, R95p, R99p, GSL and TXn) positive, negative, and insignificant trends were obtained. Generally, there were negative trends in R10mm, R20mm, R25mm, CDD, PRCPTOT, FD, TN10p, TX10p, CSDI and positive trends in Rx1DAY, SDII, SU25, TR20, TXx, TNn, TNx, TN90p, TX90p and WSDI at most stations. There is a decreasing trend in the magnitude and frequency of cold extremes and an increasing trend in magnitude and frequency of warm extremes over the observational record, which is consistent with previous research reporting the warming trends of the climate.
\end{abstract}

\section{Keywords}

Climate Change, Extreme Temperature, Extreme Precipitation, Iran, RClimdex

\section{Introduction}

Climate change research has recently gained momentum due to the economic, financial and social implications related to extreme weather events. Part of the observed twentieth century average global temperature increases may be due to 
atmosphere-ocean interactions that have strengthened the intensity of extreme events. Considerable research has focused on changes in climate extremes on global, regional and national scales. These studies generally indicate that the frequency and intensity of cool minimum temperature extremes have decreased significantly. The frequency and intensity of warm maximum temperature extremes have also increased but those trends are generally weaker. The frequency of precipitation extremes over land has increased, especially in the mid and high-latitude regions [1]. The extreme climate indices used in many studies are coordinated by the World Meteorological Organization (WMO), Commission for CLimatology (CCL), CLImate VARiability and Predictability (CLIVAR), Joint Commission for Oceanography and Marine Meteorology (JCOMM), and the Expert Team on Climate Change Detection and Indices (ETCCDI) who facilitated several workshops in data-sparse regions of the globe. Several global studies have examined temperature and precipitation extremes and found significant trends in extreme temperatures and precipitations indices [2]. Annual trends in the intensity of cool and warm maximum and minimum temperature have increased over the twentieth century in many locations throughout the world [3]. Significant increasing trend in extreme temperature indices was found over the last 110 years, with a stronger trend in the last three decades. Rainfall changes are more spatially heterogeneous compared to temperature. Still, most areas showed significant increasing trend in total extreme precipitation, precipitation intensity, and precipitation frequency [4]. Many studies have examined trends in the extreme indices over various regions. Extreme temperature and precipitation indices at 70 weather stations were studied in the Mongolian plateau over the period of 1951-2012, including events such as droughts, floods, and snow storms. Both warm and cold indices showed more intense warming trend at night [5]. Extreme precipitation indices in the present over 1970-1989 were studied in Antalya, Turkey. All study stations showed significant increasing trend [6]. Minimum temperature based indices and those indices related to heavy precipitation frequency and intensity in South Korea had a significant warming trend during the period of 1971 to 2100 ; but the trends were not significant for indices based on maximum temperature. There are increases in extreme precipitation indices in northern Portugal between 1950 and 2000 [7] [8]. Trends in extreme precipitation indices in Bangladesh over were assessed for period 1985-2007 [9]. A decreasing trend was observed in consecutive dry days. Precipitation trends were studied in the Orissa region over from 1971 to 2010, finding increasing precipitation in several months [10]. The relations of trends of extreme temperature and precipitation indices were assessed with spatial factors in three climates (hot-dry, hot-humid, and cold-dry). Proximity to the sea is associated with insignificant trends in coastal regions. However, there are fewer significant trends at high altitude stations [11]. Average Iranian climate trends have been evaluated in several national studies [12] [13] [14] [15] [16]. They found significant trends in both temperature (minimum and maximum) and precipitation in a high-quality Iranian data set over the period 1951-1997. Min- 
imum temperature is increasing at all stations except Oroomieh, which is northwest Iran. The spatial dependence and significant warming trends in extreme temperature indices over 1961-2010 were studied, as central Iran warmed more than other regions [17]. The southern half of Zagros Mountains and Shahrekord were cooling. For precipitation indices, positive significant trends were seen in southwestern Iran and the Persian Gulf coast [18]. Trends in extreme weather events were examined in north-east of Iran during 1992-2012. Trends over all precipitation indices and study stations show a general decrease, but were not significant [19]. In all studies previously conducted on this subject in Iran, extremes have been investigated based on short time period of data. In this study, the spatial and temporal distribution of extreme events in Iran will be assessed thoroughly at 33 synoptic stations as of 2014 .

\section{Materials and Methods}

\subsection{Study Area and Data}

The Iranian plateau is located between $25^{\circ} \mathrm{N}-40^{\circ} \mathrm{N}, 44^{\circ} \mathrm{E}-64^{\circ} \mathrm{E}$. Iran is mostly $(>75 \%)$ arid and semi-arid as most of the country is under the influence of subtropical high pressure. Iran has a variable climate. Winter in northwest Iran is cold (subfreezing temperatures) with heavy snowfall. Spring and fall in northwest Iran are relatively mild, while summers are dry and hot. Southern Iran is mild in winter and very hot as daily average temperature exceeds $38^{\circ} \mathrm{C}$ in July. In most of the country, the annual average precipitation is about $250 \mathrm{~mm}$, which falls from October through April. However in the higher mountain valleys of the Zagros and the Caspian coastal plain precipitation averages over $500 \mathrm{~mm}$. The western Caspian has little seasonal cycle in rainfall that exceeds $1000 \mathrm{~mm}$ per year, while in the Central Plateau there is less than $100 \mathrm{~mm}$ annually [20]. Considering the importance of the standard normal period 1961-1990 our study is also based on the use of the data for this period. So in this study the period of 1960-2014 was considered. The station locations are shown in Figure 1. Our selection covered all climatic regions.

\subsection{Statistical Tests}

\subsubsection{Run Test}

Data series are called homogeneous when they consist of samples from a single population. To run statistical tests on a series to determine population parameters, the studied series must be homogenous. This study uses the non-graphic homogeneity test known as the Run test [21]. This test is performed using the software SPSS. In this test, data is assumed to be random, and rejection of this assumption will mean that data are not random. Therefore, if the significance level is less than $5 \%$, it is concluded that the data is homogenous.

\subsubsection{Kolmogorov-Smirnov Test}

To select the proper test for analyzing the normality of the data, first the statistical distribution of the variable that is to be tested must be checked to comply 


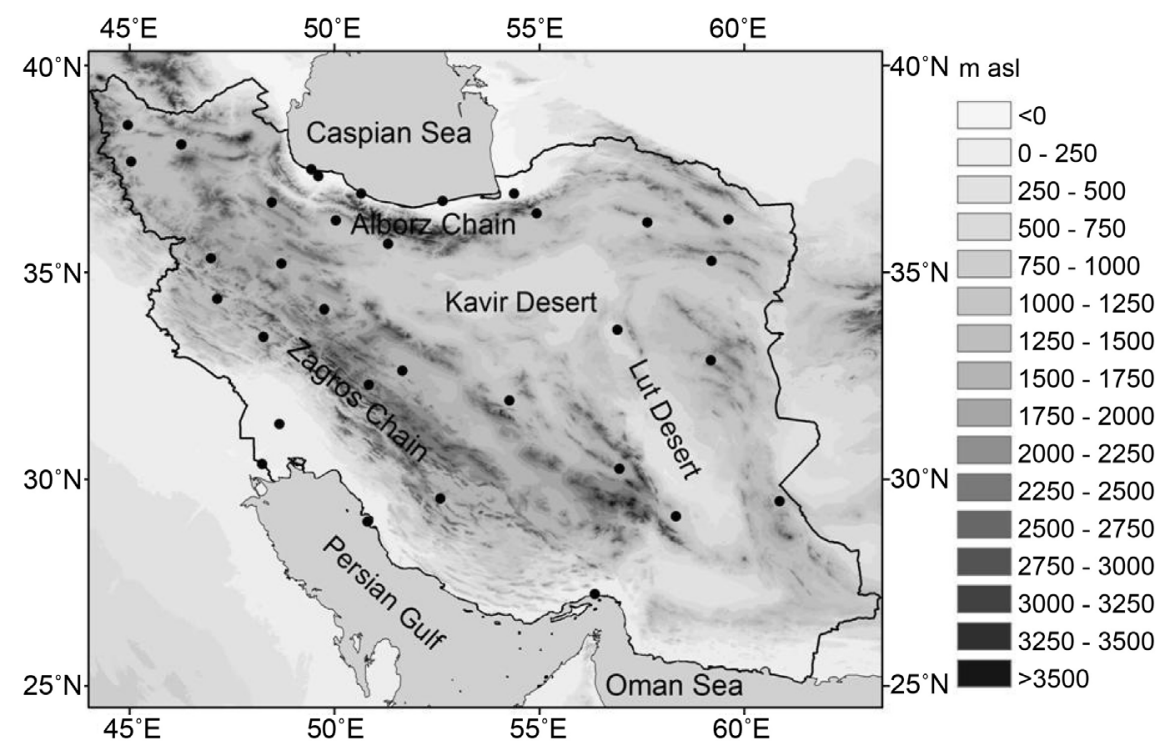

Figure 1. Spatial distribution of the synoptic stations.

with assumptions. For example, basic assumption of parametric tests is the normality of the statistical distribution of variables. The Kolmogorov-Smirnov test in the SPSS software is designed to identify the data with normal, uniform, Poisson and exponential distributions. Here, we use this test to check the normality of data. In this test, the null hypothesis is based on the normal distribution of data. Therefore, if the null hypothesis is rejected, it means that the data lack a normal distribution. In the normality test, if significance level is more than $5 \%$, it is concluded that distribution is normal [22].

\section{1) Mann-Kendall Test}

Trend analysis is an important statistical method that is widely used for evaluation of the potential effects of climate time series such as observation series pertaining to temperature, precipitation, river flow, etc. in different places. The Mann-Kendall test is one of most common and widely used non-parametric methods for analyzing the trend of time series. Using the Mann-Kendall method, one can identify the trend in data and determine its type and time period [10].

\section{2) RClimDex}

RClimDex is based on the R statistical computing environment and provides a user-friendly interface to calculate climate extreme indices for the purpose of monitoring and detecting climate change. RClimDex computes all 27 core indices recommended by the CCl/CLIVAR Expert Team. We use 16 extreme temperature and 11 extreme precipitation indices as recommended by the ETCCDI (Table 1).

\section{Results and Discussion}

\subsection{Statistical Tests}

The Run Test and Kolmogorov-Smirnov statistical tests for the parameters of rainfall, maximum temperatures and minimum temperature were calculated 
Table 1. ETCCDI extreme indices.

\begin{tabular}{|c|c|c|c|c|}
\hline & ID & Indicator name & Definitions & Units \\
\hline 1 & FD & Frost days & Annual count when $\mathrm{TN}$ (daily minimum) $<0^{\circ} \mathrm{C}$ & Days \\
\hline 2 & SU25 & Summer days & Annual count when TX (daily maximum) $>25^{\circ} \mathrm{C}$ & Days \\
\hline 3 & ID & Ice days & Annual count when TX (daily maximum) $<0^{\circ} \mathrm{C}$ & Days \\
\hline 4 & TR20 & Tropical nights & Annual count when TN (daily minimum) $>20^{\circ} \mathrm{C}$ & Days \\
\hline 5 & GSL & Growing season length & $\begin{array}{l}\text { Annual ( } 1 \text { Jan-31 Dec in NH; } 1 \text { July-30 June in SH) count between first } \\
\text { span of at least } 6 \text { days with daily mean temperature } \mathrm{T}>5^{\circ} \mathrm{C} \text { and first } \\
\text { span after July 1st (January 1st in } \mathrm{SH} \text { ) of } 6 \text { days with } \mathrm{T}<5^{\circ} \mathrm{C} \text {. }\end{array}$ & Days \\
\hline 6 & TXx & $\operatorname{Max} \operatorname{Tmax}$ & Monthly maximum value of daily maximum temperature & ${ }^{\circ} \mathrm{C}$ \\
\hline 7 & TXn & $\operatorname{Min} \operatorname{Tmax}$ & Monthly minimum value of daily maximum temperature & ${ }^{\circ} \mathrm{C}$ \\
\hline 8 & $\mathrm{TNx}$ & Max Tmin & Monthly maximum value of daily minimum temperature & ${ }^{\circ} \mathrm{C}$ \\
\hline 9 & $\mathrm{TNn}$ & Min Tmin & Monthly minimum value of daily minimum temperature & ${ }^{\circ} \mathrm{C}$ \\
\hline 10 & TN10p & Cool nights & Percentage of days when $\mathrm{TN}<10$ th percentile & Days \\
\hline 11 & TX10p & Cool days & Percentage of days when TX $<10$ th percentile & Days \\
\hline 12 & TN90p & Warm nights & Percentage of days when TN $>90$ th percentile & Days \\
\hline 13 & TX90p & Warm days & Percentage of days when TX $>$ 90th percentile & Days \\
\hline 14 & WSDI & Warm spell duration indicator & $\begin{array}{l}\text { Annual count of days with at least } 6 \text { consecutive days when } \\
\qquad \text { TX }>90 \text { th percentile }\end{array}$ & Days \\
\hline 15 & DTR & Diurnal temperature range & Monthly mean difference between TX and TN & Days \\
\hline 16 & CSDI & Cold spell duration indicator & $\begin{array}{l}\text { Annual count of days with at least } 6 \text { consecutive days when } \\
\qquad \mathrm{TN}<10 \text { th percentile }\end{array}$ & Days \\
\hline 17 & RX1day & Max 1-day precipitation & Monthly max 1-day precipitation & $\mathrm{mm}$ \\
\hline 18 & RX5day & Max 5-day precipitation & Monthly max consecutives 5 -day precipitation & $\mathrm{mm}$ \\
\hline 19 & SDII & Simple daily intensity index & $\begin{array}{l}\text { Annual total precipitation divided by the number of wet days } \\
\text { (defined as } P R \geq 1.0 \mathrm{~mm} \text { ) }\end{array}$ & Mm day ${ }^{-1}$ \\
\hline 20 & $\mathrm{R} 10$ & No. of heavy precipitation days & Annual count of days when $P R \geq 10 \mathrm{~mm}$ & Days \\
\hline 21 & $\mathrm{R} 20$ & No. of very heavy precipitation days & Annual count of days when $P R \geq 20 \mathrm{~mm}$ & Days \\
\hline 22 & $\mathrm{R} 25$ & No. of days above $25 \mathrm{~mm}$ & Annual count of days when $P R \geq 25 \mathrm{~mm}$ & Days \\
\hline 23 & $\mathrm{CDD}$ & Consecutive dry days & Max number of consecutive days with $\mathrm{RR}<1 \mathrm{~mm}$ & Days \\
\hline 24 & CWD & Consecutive wet days & Max number of consecutive days with $\mathrm{RR} \geq 1 \mathrm{~mm}$ & Days \\
\hline 25 & R99p & Very wet days & Annual total PRCP when PR $>$ 95th percentile & $\mathrm{mm}$ \\
\hline 26 & R95p & Extremely wet days & Annual total PRCP when PR $>$ 99th percentile & $\mathrm{mm}$ \\
\hline 27 & PRCPTOT & Annual total wet-day precipitation & Annual total PRCP in wet days ( $P R \geq 1 \mathrm{~mm}$ ) & $\mathrm{mm}$ \\
\hline
\end{tabular}

with SPSS. According to the results of the Run Test and Kolmogorov-Smirnov test, 33 of the 37 stations were homogenous and normal.

\subsection{Extreme Temperature}

At 18 of the 33 stations, the trend in FD is significant (95\% confidence level). For other indices, the number of stations that show significance at $95 \%$ confidence level are as follows: 20 stations for SU25, 24 stations for TR20, 8 stations for 
GSL, 13 stations for TXx, 16 stations for TNn, 26 stations for TNx, none for TXn, 23 stations for TN10p, 14 stations for TX10p, 27 stations for TN90p, 23 stations for TX90p, 22 stations for WSDI, 12 stations for CSDI, and 26 stations for DTR. Therefore, it can be said that among all extreme temperature indices, the most significant trends are found for TN90p, while the least significant trends are found for TXn, as no station has shown any significance (Table 2).

Table 2. Decadal trends in temperature indices for selected stations $\left({ }^{\circ} \mathrm{C}\right)$.

\begin{tabular}{|c|c|c|c|c|c|c|c|c|c|c|c|c|c|c|c|}
\hline Station & FD & SU25 & TR20 & GSL & TXx & TNn & TNx & TXn & TN10p & TX10p & TN90p & TX90p & WSDI & CSDI & DTR \\
\hline Abadan & 0.0 & 0.1 & $0.8^{*}$ & -0.0 & $0.6^{*}$ & 0.2 & $0.3^{*}$ & -0.3 & $-1.2^{*}$ & $-0.8^{*}$ & $3.9^{*}$ & $3.6^{*}$ & $4.7^{\star}$ & -4.3 & -0.1 \\
\hline Ahvaz & $-0.1^{\star}$ & $0.2^{*}$ & $1.1^{*}$ & -0.1 & $0.4^{*}$ & 0.6 & $7.9^{*}$ & -0.1 & $-2.4^{*}$ & -0.7 & $7.4^{*}$ & $2.7^{\star}$ & $3.4^{*}$ & $-1.4^{*}$ & $-0.5^{*}$ \\
\hline Anzali & $-0.1^{\star}$ & 0.0 & $1.1^{*}$ & 1.0 & -0.2 & 0.4 & $0.7^{*}$ & -0.0 & $-1.7^{\star}$ & 0.7 & $6.3^{*}$ & -0.4 & 0.2 & -0.8 & $-0.5^{*}$ \\
\hline Arak & $0.3^{*}$ & 0.1 & $0.4^{\star}$ & -2.2 & 0.1 & 0.2 & $0.4^{*}$ & -0.1 & -0.6 & 0.1 & 0.6 & 0.3 & 1.4 & -0.2 & -0.0 \\
\hline Babolsar & $-0.1^{\star}$ & $0.6^{*}$ & $1.1^{*}$ & 1.8 & 0.1 & $0.5^{*}$ & $0.4^{*}$ & 0.2 & $-1.9^{*}$ & $-0.8^{*}$ & $5.5^{*}$ & $1.9^{*}$ & $4.4^{*}$ & -0.1 & $-0.3^{*}$ \\
\hline Bam & -0.1 & $0.2^{*}$ & $0.9^{*}$ & 0.7 & $0.4^{*}$ & $0.5^{*}$ & $6.5^{*}$ & -0.1 & $-2.1^{*}$ & $-0.9^{*}$ & $5.4^{*}$ & $2.4^{*}$ & $3.2^{*}$ & $-1.7^{\star}$ & $-0.3^{*}$ \\
\hline Bandar Abbas & 0 & 0.1 & 0.2 & -0.0 & 0.3 & $-0.5^{\star}$ & 0.0 & -0.0 & 0.7 & 0.9 & 0.8 & $0.9^{*}$ & 0.8 & 0.9 & 0.1 \\
\hline Birjand & 0.1 & 0.2 & 0.1 & 0.1 & -0.1 & $-0.9^{\star}$ & 0.1 & -0.2 & $0.9^{*}$ & 0.7 & $1.0^{*}$ & 0.3 & $1.8^{*}$ & 0.7 & 0.0 \\
\hline Bushehr & -0.1 & 0.2 & $0.9^{*}$ & -0.0 & 0.0 & $0.4^{*}$ & $3.5^{*}$ & -0.0 & $-2.7^{\star}$ & $-0.9^{\star}$ & $5.3^{*}$ & 0.7 & 0.3 & $-1.2^{\star}$ & $-0.4^{*}$ \\
\hline Esfahan & 0.0 & $0.5^{*}$ & $0.3^{*}$ & $5.1^{*}$ & $0.3^{*}$ & 0.1 & 0.2 & 0.4 & -0.1 & $-1.0^{*}$ & $1.6^{*}$ & 3. $7^{\star}$ & $7.7^{\star}$ & 0.6 & 0.2 \\
\hline Gorgan & $0.2^{*}$ & $0.3^{*}$ & $0.4^{*}$ & 0.3 & -0.0 & -0.1 & $0.4^{*}$ & 0.2 & 0.6 & $-0.9^{\star}$ & $1.5^{*}$ & 0.5 & $1.2^{*}$ & 0.3 & 0.1 \\
\hline Hamedan & 0.1 & $0.2^{*}$ & 0.0 & -1.3 & 0.1 & 0.3 & 0.1 & 0.1 & $-1.1^{\star}$ & -0.5 & 0.3 & 0.7 & $1.7^{*}$ & -0.6 & -0.1 \\
\hline Kerman & 0.5 & $0.5^{*}$ & $0.3^{*}$ & $6.8^{*}$ & $0.3^{*}$ & $0.7^{*}$ & $0.4^{*}$ & 0.3 & $-1.7^{\star}$ & $-1.2^{\star}$ & $2.7^{*}$ & $3.2^{*}$ & $5.5^{*}$ & $-1.3^{*}$ & $-0.1^{*}$ \\
\hline Kermanshah & $-0.3^{\star}$ & $0.4^{*}$ & $0.2^{*}$ & $5.1^{*}$ & 0.1 & 0.5 & $0.4^{*}$ & 0.5 & $-1.7^{\star}$ & $-1.3^{*}$ & $3.5^{*}$ & $3.5^{\star}$ & $6.6^{*}$ & $-0.9^{*}$ & -0.1 \\
\hline Khoramabad & $0.8^{*}$ & -0.1 & 0.2 & -2.3 & $-0.3^{\star}$ & -0.4 & -0.1 & -0.1 & 1.4 & 0.0 & $-0.9^{*}$ & $-0.1^{\star}$ & -0.2 & 1.1 & $0.2^{*}$ \\
\hline Khoy & 0.1 & $0.3^{*}$ & $0.1^{*}$ & 0.9 & 0.1 & -0.2 & $0.4^{*}$ & 0.1 & $-1.1^{\star}$ & -0.6 & $2.9^{*}$ & $1.3^{*}$ & $2.8^{*}$ & -0.7 & $-0.2^{*}$ \\
\hline Mashhad & $0.9^{*}$ & $0.5^{*}$ & $0.9^{*}$ & $7.1^{*}$ & $0.4^{*}$ & $1.6^{*}$ & $0.6^{*}$ & 0.1 & $-2.2^{\star}$ & -0.5 & $7.2^{*}$ & $2.4^{*}$ & $2.4^{*}$ & -1.0 & $-0.6^{*}$ \\
\hline Oroomieh & $0.3^{*}$ & 0.2 & 0.0 & -2.6 & 0.0 & 0.1 & -0.0 & 0.2 & 0.3 & -0.5 & 0 & 1.0 & 2.2 & -0.3 & $0.2^{*}$ \\
\hline Ghazvin & -0.1 & 0.1 & 0.0 & 1.4 & 0.1 & 0.0 & 0.2 & 0.1 & -0.4 & -0.4 & $1.2^{*}$ & 0.4 & 1.4 & -0.2 & -0.1 \\
\hline Ramsar & $-0.1^{\star}$ & $0.5^{*}$ & $1.1^{*}$ & 1.6 & $0.5^{*}$ & $0.5^{*}$ & $0.6^{*}$ & -0.1 & $-0.1^{\star}$ & -0.3 & $6.5^{*}$ & $2.4^{*}$ & $6.0^{*}$ & -0.1 & $0.3^{*}$ \\
\hline Rasht & $-0.2^{\star}$ & $0.3^{*}$ & $1.2^{\star}$ & 2.8 & 2.4 & $0.7^{*}$ & $0.5^{*}$ & -0.2 & $-2.3^{*}$ & 0.1 & $4.2^{*}$ & $1.1^{*}$ & $2.9^{*}$ & -1.3 & $-0.4^{*}$ \\
\hline Sabzevar & $-0.7^{\star}$ & $0.4^{*}$ & $0.9^{*}$ & $5.2^{*}$ & 0.1 & $1^{*}$ & $0.4^{*}$ & 0.3 & $-2.5^{\star}$ & -0.7 & $4.1^{\star}$ & $1.5^{\star}$ & $2.6^{*}$ & -1.7 & $-0.4^{*}$ \\
\hline Sanandaj & -0.2 & $0.4^{*}$ & $0.2^{*}$ & 3.3 & $0.2^{*}$ & $0.9^{*}$ & $0.4^{*}$ & 0.4 & -0.8 & $-1.5^{\star}$ & $2.4^{*}$ & $3.2^{*}$ & $6.4^{*}$ & -0.3 & $0.2^{*}$ \\
\hline Shahrekord & $0.6^{*}$ & -0.1 & 0 & $-5.1^{\star}$ & $-0.4^{\star}$ & -0.5 & $-0.4^{*}$ & 0.5 & $4.4^{*}$ & 0.3 & $-0.7^{\star}$ & $-0.9^{*}$ & 0.3 & 4. $8^{*}$ & $0.3^{*}$ \\
\hline Shahrod & $-0.5^{\star}$ & $0.3^{*}$ & $0.9^{*}$ & 0.6 & $0.3^{*}$ & $0.5^{\star}$ & $0.8^{*}$ & -0.1 & $-2.1^{\star}$ & -0.4 & $5.0^{*}$ & $0.4^{*}$ & 0.8 & $-1.0^{\star}$ & $-0.6^{*}$ \\
\hline Shiraz & -0.2 & $0.4^{\star}$ & $0.9^{*}$ & 1.9 & $0.2^{*}$ & 0.4 & $0.5^{\star}$ & 0.4 & $-1.9^{*}$ & $-1.1^{*}$ & $5.4^{*}$ & $2.1^{*}$ & $4.1^{\star}$ & -0.7 & $-0.3^{*}$ \\
\hline Tabas & $-0.5^{\star}$ & 0.1 & $1.5^{*}$ & 0.8 & 0.2 & $0.4^{*}$ & $0.6^{*}$ & -0.3 & $-2.8^{*}$ & 0.3 & $9.4^{*}$ & $1.3^{*}$ & $2.8^{*}$ & $-2.3^{*}$ & $-0.9^{*}$ \\
\hline Tabriz & 0.0 & $0.2^{*}$ & 0.1 & -2.0 & -0.1 & $-0.6^{*}$ & $-0.2^{\star}$ & -0.4 & 0.1 & 0.1 & 0.1 & 0.1 & 0 & 0 & 0.0 \\
\hline Tehran & $-0.5^{\star}$ & $0.3^{*}$ & $0.9^{*}$ & $4.9^{*}$ & 0.1 & $0.8^{*}$ & $0.4^{*}$ & 0.3 & $-2.0^{*}$ & $-0.8^{\star}$ & $4.4^{*}$ & $1.6^{*}$ & $3.1^{*}$ & $-1.3^{*}$ & $-0.4^{*}$ \\
\hline Torbtheydar & 0.0 & -0.1 & $0.6^{*}$ & -3.3 & $-0.4^{*}$ & 0.4 & $0.2^{*}$ & -0.2 & $-0.8^{*}$ & $1.5^{*}$ & $2.1^{*}$ & $-1.1^{*}$ & $-1.2^{\star}$ & $-0.9^{*}$ & $-0.5^{*}$ \\
\hline Yazd & $-0.6^{*}$ & $0.5^{*}$ & $0.9^{*}$ & $3.1^{*}$ & 0.7 & $0.9^{*}$ & $0.7^{*}$ & 0.1 & $-2.3^{*}$ & $-1.0^{\star}$ & $5.7^{\star}$ & $2.6^{*}$ & $4.7^{*}$ & $-1.8^{\star}$ & $-0.4^{*}$ \\
\hline Zahedan & $-0.2^{*}$ & $0.4^{*}$ & $0.7^{*}$ & 1.7 & 0.1 & 0.5 & $0.5^{\star}$ & 0.1 & $-1.6^{*}$ & $-0.7^{\star}$ & $2.5^{*}$ & $1.5^{*}$ & $2.1^{*}$ & $-1.9^{*}$ & $-0.3^{*}$ \\
\hline Zanjan & -0.0 & 0.1 & 0.0 & -2.9 & 0.0 & 0.1 & $0.1^{*}$ & 0.2 & -0.4 & -0.2 & 0.7 & 0.2 & 1.2 & -0.3 & -0.1 \\
\hline
\end{tabular}

"*"indicates the significancy of trend at the level of $95 \%$. 


\subsection{Frost Days}

The trend in frost days varies between stations, with both increasing and decreasing trends. Twenty-on (21) of the 33, (64\%) stations have a negative and decreasing trend and 12 stations have an increasing trend. Of the 18 stations that have a significant trend for frost days, 13 have a decreasing trend and only 5 stations have an increasing trend. Khoram Abad has the sharpest increasing trend in the number of frost days, which is 0.76 day per year. This means that from 1960 to 2014 every 10 years the number of frost days in Khoram Abad has increased by 7.6 days. Mashhad has the sharpest decreasing trend in the number of frost years, which is -0.86 day per year, which means that the number of frost days has decreased by 8.6 days every 10 years (Figure 2(a)).

In all Figures 2-6 the P-value amounts for trends are 0.

\subsection{Summer Days}

The trend in SD is shown in Table 2 and Figure 2(b) (for some stations). Ninety-one percent (91\%) of the stations have an increasing trend and only 3 stations have a decreasing trend. All 20 stations with significant trend have an increasing trend. Babolsar and Kerman have the greatest increasing trend in SD, which is equal to 0.55 day per year. This means that from 1960 to 2014, every 10 years the number of summer days has increased by 5.5 . Shahre Kord has the sharpest decreasing trend that is equal to 0.11 days per year, or 1.1 days less every ten years.

\subsection{Tropical Nights}

In all stations, there is an increasing trend in the index of tropical nights (Table 2, Figure 2(c)). Tabas has the sharpest increasing trend in the number of tropical nights, which is equal to 1.48 days per year. This means that from 1960 to 2014, every 10 years the number of tropical nights has increased by 14.8 days.

\subsection{Growing Season Length}

Eight (8) stations had significant trends in GSL, while 7 of these 8 stations had an increasing trend. Shahre Kord had a trend of 5 days decrease in the growing season length per 10 years. Mashhad has the sharpest increase in growing season length, which is about a 7 day increase every ten years (Figure 2(d)).

\subsection{Max Tmin}

26 stations had a significant trend for TNx. The greatest increasing trend, 7.9 days per ten years, is seen in Ahvaz. Shahrod exhibits the sharpest decreasing trend that is equal to -0.37 days per ten years (Figure $2(e)$ ).

\subsection{Min Tmin}

Eighteen (18) of the 33 stations had a significant trend for TNn. Mashhad station has the sharpest increase, which is 1.62 days per ten years, and Birjand stations exhibits the sharpest decrease, which is $-0.97^{\circ} \mathrm{C}$ per ten years, (Figure $2(\mathrm{f})$ ). The 

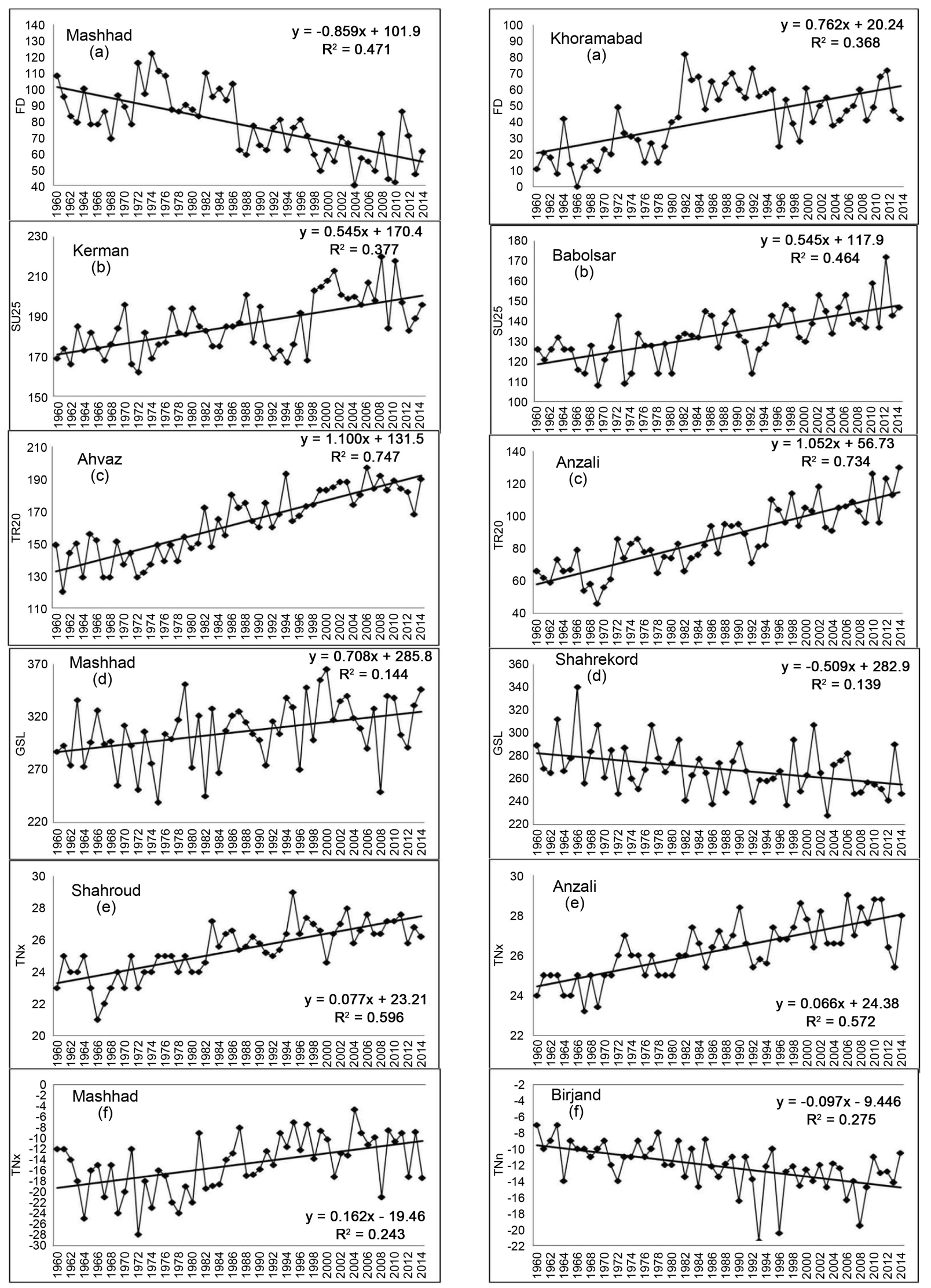

Figure 2. Time series of FD (a), SU25 (b), TR20 (c), GSL (d), TNx (e) and TNn (f) indices. 


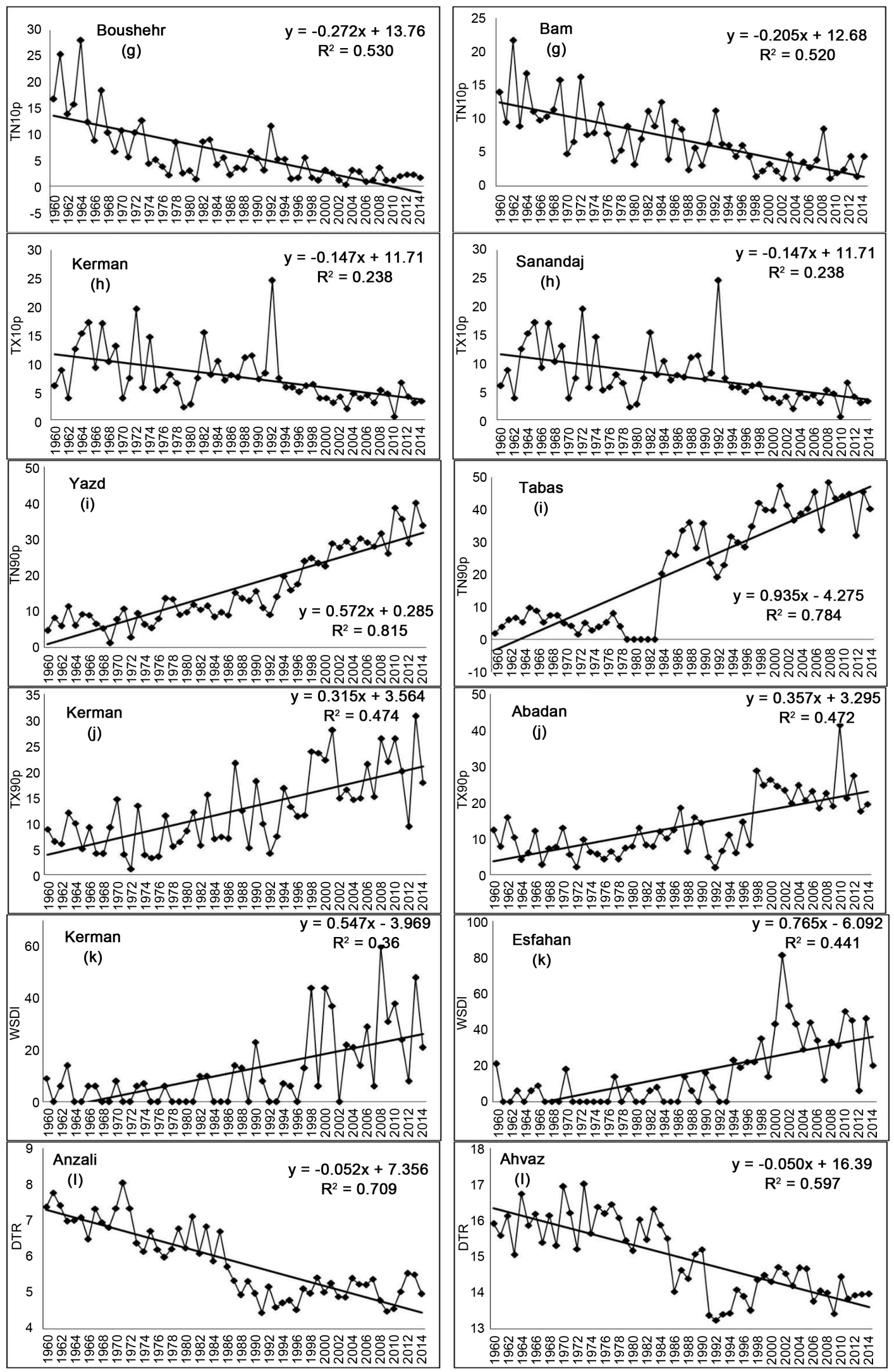

Figure 3. Time series of TN10p (g), TX10p (h), TN90p (i), TX90p (j), WSDI (k) and DTR (l) indices in 12 selected stations. 
M. Rahimi et al.
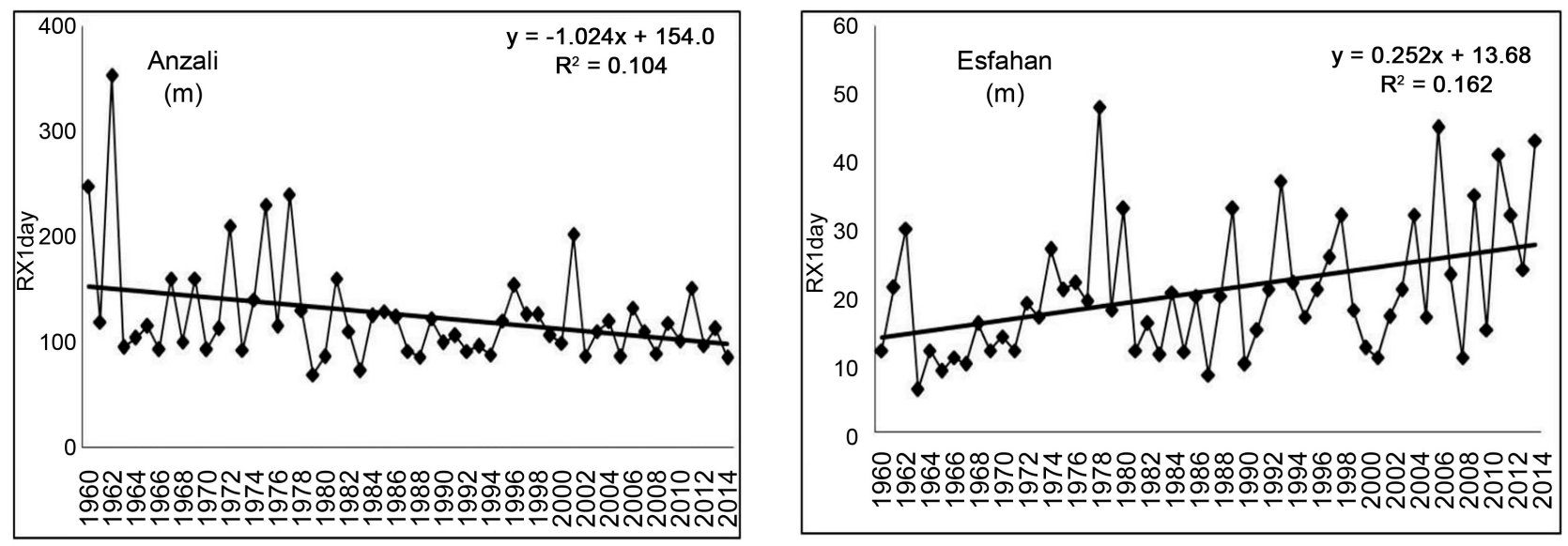

Figure 4. Time series of CSDI (m) index in 2 selected stations.
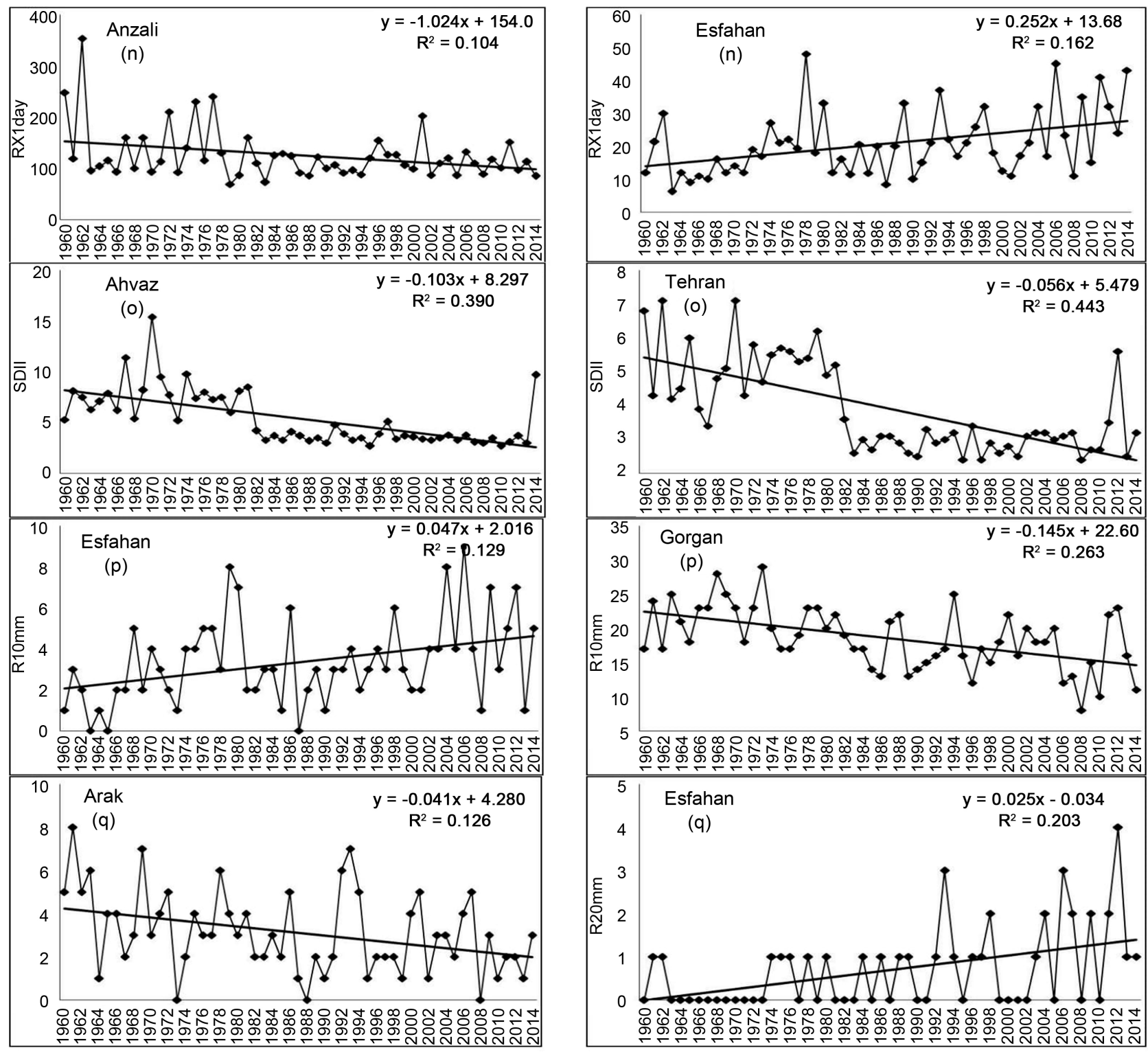

Figure 5. Time series of RX1day (n), SSDII (o), R10mm (p) and R20mm (q) indices in 8 selected stations. 

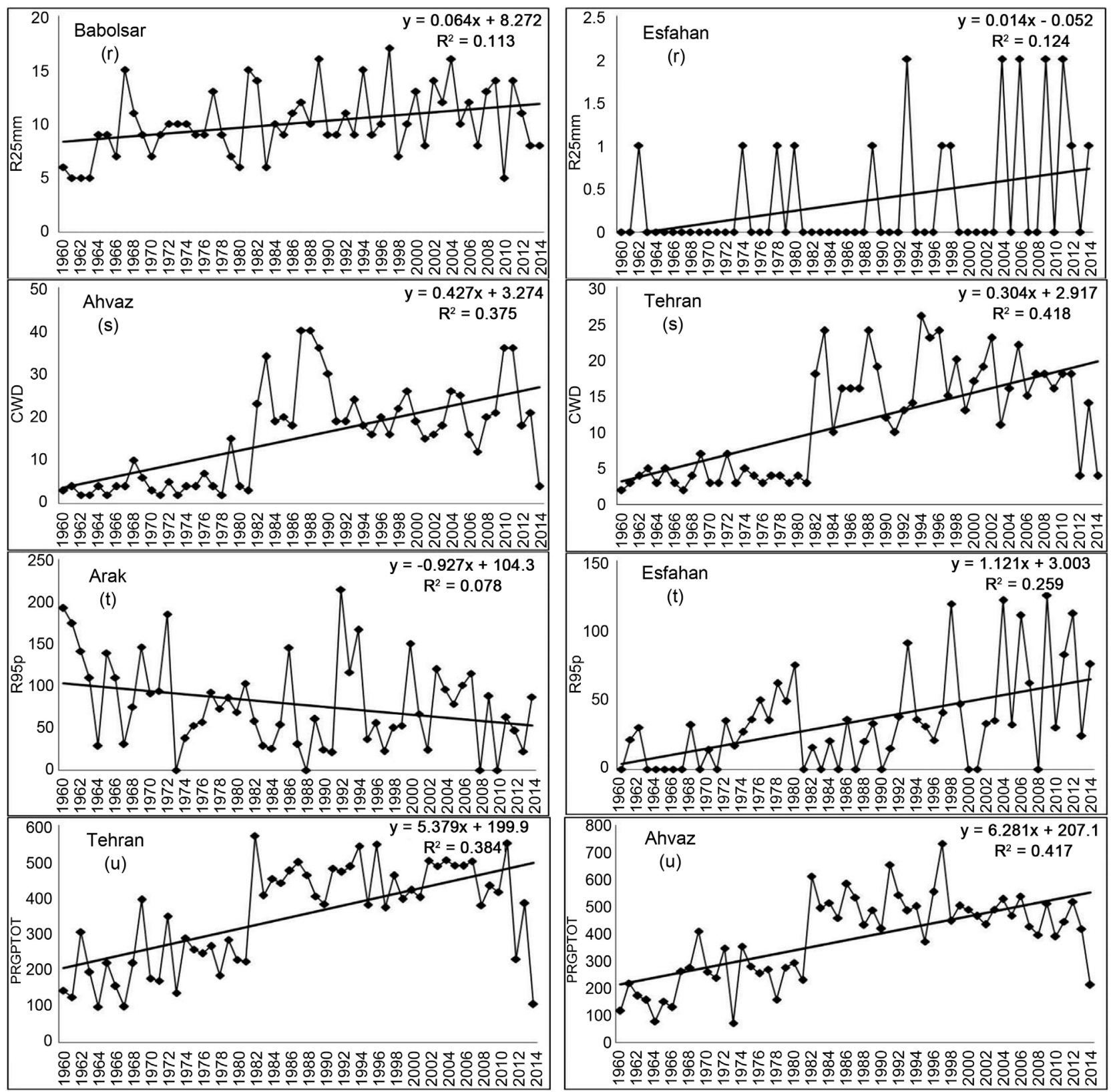

Figure 6. Time series of R25mm (r), CWD (s), R95p (t) and PRCPTOT (u) indices in 8 selected stations.

$\mathrm{P}$ value of both trends is 0 .

\subsection{Cool Nights}

Of the 33 stations, 23 had a significant trend for this index. Share Kord station has the sharpest increasing trend, (4.39 days per ten years) and Tabas Station has the sharpest decreasing trend ( -2.78 days each ten years) in the number of cool nights. Figure $3(\mathrm{~g})$ shows the trend of changes for 2 selected stations.

\subsection{Cool Days}

Of the total number of stations, 14 stations had a significant trend for this index. 
Tarbat Heydarieh station (1.46 days per ten years) had the sharpest increasing trend in the number of cool days, while Sannandaj station ( -1.48 days per ten years) had the sharpest decreasing trend (Figure $3(\mathrm{~h})$ ).

\subsection{Warm Nights}

Approximately $85 \%$ of the stations had a significant trend for warm nights. Tabas station, with a trend of 9.35 day each ten years, had the sharpest increasing trend, while Khorram Abad station, with a trend of -0.85 days per ten years, had the greatest decreasing trend. Figure 3(i) shows the trend diagram of 2 selected stations.

\subsection{Warm Days}

Twenty-three (23) of the 33 stations had a significant trend for this index. Esfahan, with a trend of 3.67 days per ten years, had the sharpest increasing trend and Tarbat Heydarieh station with a trend of -1.13 days per ten years had the sharpest decreasing trend (Figure $3(j))$.

\subsection{Warm Spell Duration Indicator}

Similarly, 22 of the 33 stations had a significant trend for the warm spell duration index. Esfahan station with a trend of 7.66 days per ten years had the sharpest increasing trend and Tarbat Heydarieh station with a trend of -1.2 days per ten years had the sharpest decreasing trend. Figure $3(\mathrm{k})$ shows the trend changes of 2 selected stations.

\subsection{Diurnal Temperature Range}

Twenty-tow (22) of the 33 stations had a significant trend for this index. Sharekord station with a trend of 0.31 days per ten years had the sharpest increasing trend and Tabas station with a trend of -0.95 days per ten years had the sharpest decreasing trend. Figure 3(1) shows the trend of DTR index in 2 selected stations.

\subsection{Cold Spell Duration Indicator}

Only 12 of the 33 stations had a significant trend for this index. Shahrekord station with a trend of 4.78 days per ten years had the sharpest increasing trend. Abadan station with a trend of -4.30 days per ten years had the sharpest decreasing trend. Figure $4(\mathrm{~m})$ shows the trend of changes in CSDI index for Share Kord and Yazd stations.

\subsection{Max Tmax}

Similarly, only 13 of the 33 stations had a significant trend of daily changes for this index. Rasht station with a trend of 2.4 degrees per ten years had the sharpest increasing trend and Shahre Kord station with a trend of 0.37 degrees per ten years had the sharpest decreasing trend. 
Considering the results presented above, it can be concluded that more than half of the extreme temperature indices had an increasing trend. For example, 9 indices had an increasing trend in nearly all stations while 7 other indices had a decreasing trend. FD index had 12 decreasing trends and 4 increasing trends from the total of 16 stations that had a significant trend. For SU25, 30 stations had increasing trends and 3 had decreasing trends; out of these 20 stations had a significant increasing trend. No significant trend was seen for ID and TXn indices. In 24 stations, TR20 index showed a significant increasing trend during the studied period. The indices GSL, TXx, TNn, TNx, TN90p, TX90p and WSDI showed increasing trends and TN10p, CSDI and DTR showed decreasing trends over the study period.

The results of this study show a significant warming trend for extreme temperature indices in many of the stations. For example, of the 33 stations, 29 stations for TNx, 14 stations for TNn, 21 and 25 stations for TN10p and TN90p indices, and 13 and 24 stations for FD and TR indices show a significant warming trend. Overall, the changes in TX10p and TX90p are of lesser magnitude than those in cold and warm nights. Also the time trend of TXn and TXx is lesser of magnitude than that of the coldest and warmest nights. The highest frequency of significant change in temperature indices were observed in the stations Tehran, Yazd, Kerman, Bam and Mashhad and the lowest frequency was observed in stations Zanjan, Ghazvin, Oromiye and Bandar Abbas.

\subsection{Extreme Precipitation}

Table 3 shows the trend of changes of extreme precipitation indices for $33 \mathrm{stu}$ died stations. The trends at only a relatively few number of stations are significant at a 95\% confidence level. The number of stations with significant trends (at a 95\% confidence level) for each index are as follows: 2 stations for RX1day index, 1 station for RX5day index, 5 stations for SDII index, 6 stations for R10mm index, 5 stations for R20mm index, 2 stations for R25mm index, 2 stations for R25mm index, 2 stations for CDD index, 6 stations for CWD index, 3 stations for R95p index, 1 station for R99p index and 6 stations for PRCPTOT index. The number of these stations is less than what was observed for extreme temperature indices.

\subsection{Max 1-Day Precipitation}

Only Anzali and Esfahan stations had a significant trend for this index. Esfahan station had an increasing trend of 2.53 millimeters per ten years and Anazli station had a decreasing trend of -10.24 millimeters per ten years (Figure $5(n)$ ).

\subsection{Simple Daily Intensity Index}

A minimal number of stations (12\%), had a significant trend for this index. Esfahan station had an increasing trend of 0.46 millimeters per ten years. Anazli station had a decreasing trend of -1.4 millimeters per ten years (Figure 5(o)). 
Table 3. Decadal trends in precipitation indices for selected stations.

\begin{tabular}{|c|c|c|c|c|c|c|c|c|c|c|c|}
\hline Station & Rx1day & Rx5day & SDII & $\mathrm{R} 10 \mathrm{~mm}$ & $\mathrm{R} 20 \mathrm{~mm}$ & $\mathrm{R} 25 \mathrm{~mm}$ & CDD & CWD & R95p & R99p & PRCPTOT \\
\hline Abadan & 1.47 & 0.98 & 0.33 & -0.11 & 0.03 & 0.1 & -2.51 & -0.2 & 3.99 & 4.49 & 1.25 \\
\hline Ahvaz & 0.17 & 0.28 & $-1.04^{\star}$ & -0.17 & 0 & -0.06 & $-12^{\star}$ & $4.28^{\star}$ & 0.6 & -0.24 & $62.81^{*}$ \\
\hline Anzali & $-10.24^{*}$ & -7.07 & -0.03 & -0.14 & -0.02 & 0.28 & 0.79 & 0.42 & -22.53 & -23.76 & -0.85 \\
\hline Arak & -1.99 & $-5.68^{\star}$ & -0.12 & $-0.86^{\star}$ & $-0.42^{\star}$ & -0.25 & -3.88 & 0.01 & $-9.28^{\star}$ & -5.51 & $-19.25^{\star}$ \\
\hline Babolsar & 2.1 & 2.75 & 0.47 & 0.3 & $0.72^{*}$ & $0.65^{\star}$ & 1.01 & 0.32 & 16.19 & 12.18 & 29.85 \\
\hline Bam & 0.24 & -0.07 & $0.26^{*}$ & -0.05 & -0.07 & -0.01 & -4.5 & $0.2^{*}$ & 0.66 & -0.06 & -2.95 \\
\hline Bandar Abbas & 0.52 & -0.58 & 0.03 & 0.04 & -0.09 & -0.01 & -5 & 0.18 & 1.39 & 0.7 & -5.13 \\
\hline Birjand & -0.55 & -0.5 & -0.03 & -0.21 & -0.05 & 0 & -0.59 & -0.03 & -1.19 & -0.42 & 0 \\
\hline Bushehr & 2.18 & 4.12 & 1.75 & 0.24 & 0.26 & 0.23 & -1.54 & 0.03 & 4.12 & 4.71 & 10.12 \\
\hline Esfahan & $2.53^{*}$ & 1.69 & $0.46^{*}$ & $0.47^{*}$ & $0.26^{*}$ & $0.14^{*}$ & -1.65 & -0.14 & $11.21^{*}$ & $6.15^{*}$ & $11.31^{*}$ \\
\hline Gorgan & 0.71 & -1.25 & 0.02 & $-1.45^{\star}$ & -0.27 & -0.15 & 1.23 & 0 & -2.26 & 3.38 & $-28.2^{*}$ \\
\hline Hamedan & 0.38 & 0.27 & -0.18 & -0.53 & -0.12 & -0.02 & -1.85 & $0.64^{*}$ & -4.11 & -1.29 & -0.31 \\
\hline Kerman & -0.8 & -2.13 & 0.1 & -0.04 & -0.03 & -0.05 & 1.75 & $-0.42^{\star}$ & -2.43 & -1.86 & -6.36 \\
\hline Kermanshah & 3.7 & -1.68 & 0.04 & $-1.01^{*}$ & -0.24 & -0.12 & -0.1 & -0.77 & -6.04 & -0.18 & -18.76 \\
\hline Khoramabad & 1.27 & -0.39 & 0.12 & -0.59 & -0.32 & -0.1 & 0.02 & -0.28 & 0.01 & 1.5 & -12.33 \\
\hline Khoy & 0.54 & 0.21 & $0.13^{*}$ & 0.24 & -0.05 & -0.05 & -0.89 & -0.36 & -1.93 & 1.5 & -12.04 \\
\hline Mashhad & -0.8 & -0.79 & 0.07 & -0.06 & -0.02 & -0.03 & -3.39 & -0.01 & -0.37 & -1.17 & -0.38 \\
\hline Oroomieh & 1.01 & 0.5 & 0.06 & -0.63 & -0.02 & 0.02 & 0.02 & -0.38 & 1.22 & 3.07 & -10.33 \\
\hline Ghazvin & 0.62 & 0.7 & 0.09 & 0.11 & 0.08 & 4.15 & 0.27 & 0.27 & 4.15 & 1.9 & 6.62 \\
\hline Ramsar & 3.03 & 3.68 & 0.28 & 0.01 & -0.19 & -0.06 & 1.12 & 0.49 & -9.53 & 8.85 & 0.24 \\
\hline Rasht & 2.59 & 4.38 & 0.32 & -1.01 & -0.13 & 0.03 & -0.32 & -0.12 & 13.6 & 9.12 & 3.78 \\
\hline Sabzevar & -0.21 & 1.07 & 0.13 & 0.27 & 0.03 & 0 & 0.03 & 0.09 & 1.1 & -0.31 & 3.66 \\
\hline Sanandaj & -0.43 & -2.33 & -0.22 & $-0.96^{*}$ & $-0.44^{*}$ & -0.26 & -1.97 & -0.1 & -8.76 & -1.57 & $-25.95^{*}$ \\
\hline Shahrekord & -0.46 & -2.44 & -0.04 & 0.06 & 0.01 & -0.03 & -2.27 & 0.29 & -2.29 & -1.09 & 3.98 \\
\hline Shahrod & -0.16 & 0.06 & 0.01 & -0.19 & -0.06 & -0.04 & 1.09 & 0.04 & -1.81 & -1.2 & -1.74 \\
\hline Shiraz & 0.1 & 1.58 & 0.36 & -0.04 & 0.14 & 0.21 & -4.91 & 0.27 & 9.88 & 1.3 & 8.83 \\
\hline Tabas & 0.35 & 0.22 & 0.2 & 0.06 & -0.02 & 0.01 & -2.5 & 0.05 & 0.63 & -0.29 & 3.2 \\
\hline Tabriz & -0.16 & -0.16 & -0.01 & -0.36 & -0.07 & 0 & $1.47^{\star}$ & $-0.15^{*}$ & $-6.33^{*}$ & -0.19 & -7.54 \\
\hline Tehran & 0.56 & 1.08 & $-0.56^{*}$ & 0.06 & 0.12 & -0.04 & -5.47 & $3.05^{*}$ & 3.34 & -0.6 & $53.8^{*}$ \\
\hline Torbat heydar & 0.12 & -0.07 & 0.02 & -0.12 & -0.09 & 0.02 & -4.04 & 0.23 & -0.07 & 1.76 & -2.38 \\
\hline Yazd & -0.07 & 0.1 & -0.04 & 0.07 & -0.02 & -0.03 & -3.53 & 0 & 0.36 & -0.6 & -0.89 \\
\hline Zahedan & -1.05 & -1.07 & -0.2 & $-0.34^{*}$ & $-0.16^{*}$ & -0.09 & 3.91 & -0.1 & -2.95 & -1.14 & -5.13 \\
\hline Zanjan & -0.24 & -0.12 & 0.06 & -0.22 & -0.3 & -0.03 & -2.69 & 0.1 & 0.2 & -0.26 & -3.89 \\
\hline
\end{tabular}

\subsection{No. of Heavy Precipitation Days}

Arak, Esfahan, Gorgan, Kermanshah, Sanandaj and Zahedan had significant trends for this index. Esfahan station with a trend of 0.47 millimeters per ten years had the sharpest increasing trend. Gorgan station with a trend of -1.45 millimeters per ten years had the sharpest decreasing trend (Figure 5(p)). 


\subsection{No. of Very Heavy Precipitation Days}

Only seven of the total number of stations had a significant trend for this parameter. Bablosar station with a trend of 0.72 millimeters per ten years had the sharpest increasing trend. Sanandaj station with a trend of -0.44 millimeters per ten years had the sharpest decreasing trend (Figure 5(q)).

\subsection{No. of Days above $25 \mathrm{~mm}$}

Babolsar and Esfahan station had a significant trend for this index, while other stations had no significant trends. Babolsar station shows a trend of 0.65 days increase per ten years and Esfahan station shows a trend of 0.14 days increase per ten years in this index (Figure 6(r)).

\subsection{Consecutive Wet Days}

Seven stations had a significant trend for this index. Ahvaz station had an increasing trend of 4.28 days per ten years and Kerman had a decreasing trend of -0.42 days per ten years for this index (Figure 6(s)).

\subsection{Very Wet Days}

Arak, Esfahan and Tabriz had a significant trend for this index. Arak station showed a decreasing trend of $9.28 \%$ days per ten years for this index. This is while Esfahan station showed an increasing trend of $11.21 \%$ days per ten years for this index. Tabriz station showed a decreasing trend of $-6.33 \%$ for this index (Figure 6(t)).

\subsection{Annual Total Wet-Day Precipitation}

Six of 33 stations had a significant trend for this index. Ahvaz station with a trend of 62.81 millimeters per ten years had the sharpest increasing trend. Gorgan station with a trend of 28 millimeters per year had the sharpest decreasing trend (Figure 6(u)).

Only Arak station had a significant trend for "Max 5-day precipitation" index, which was equal to -5.68 millimeters perten years. Other stations had no significant trends for this index. Ahvaz and Tabriz stations had a significant trend for "Consecutive dry days" index. Ahvaz station showed a decreasing trend of 12 days per ten years for "Consecutive dry days" index. But Tabriz station showed an increasing trend of 1.47 days for this index. Only Esfahan station showed a significant trend for "Extremely wet days" index, which was $+6 \%$ per ten years. The maps of changes in some of temperature and precipitation extreme indices for selected stations across the country are presented in Figure 7 and Figure 8.

Figure 8 shows the trends of some extreme precipitation indices in selected stations during the past 55 years. The obtained maps show that CDD had generally significant negative trends; but northern stations showed significant positive trends for this index. This index was also positive in Yazd, Kerman, Zahedan and Khorramabad, but not significantly so. The index CWD was found to have 


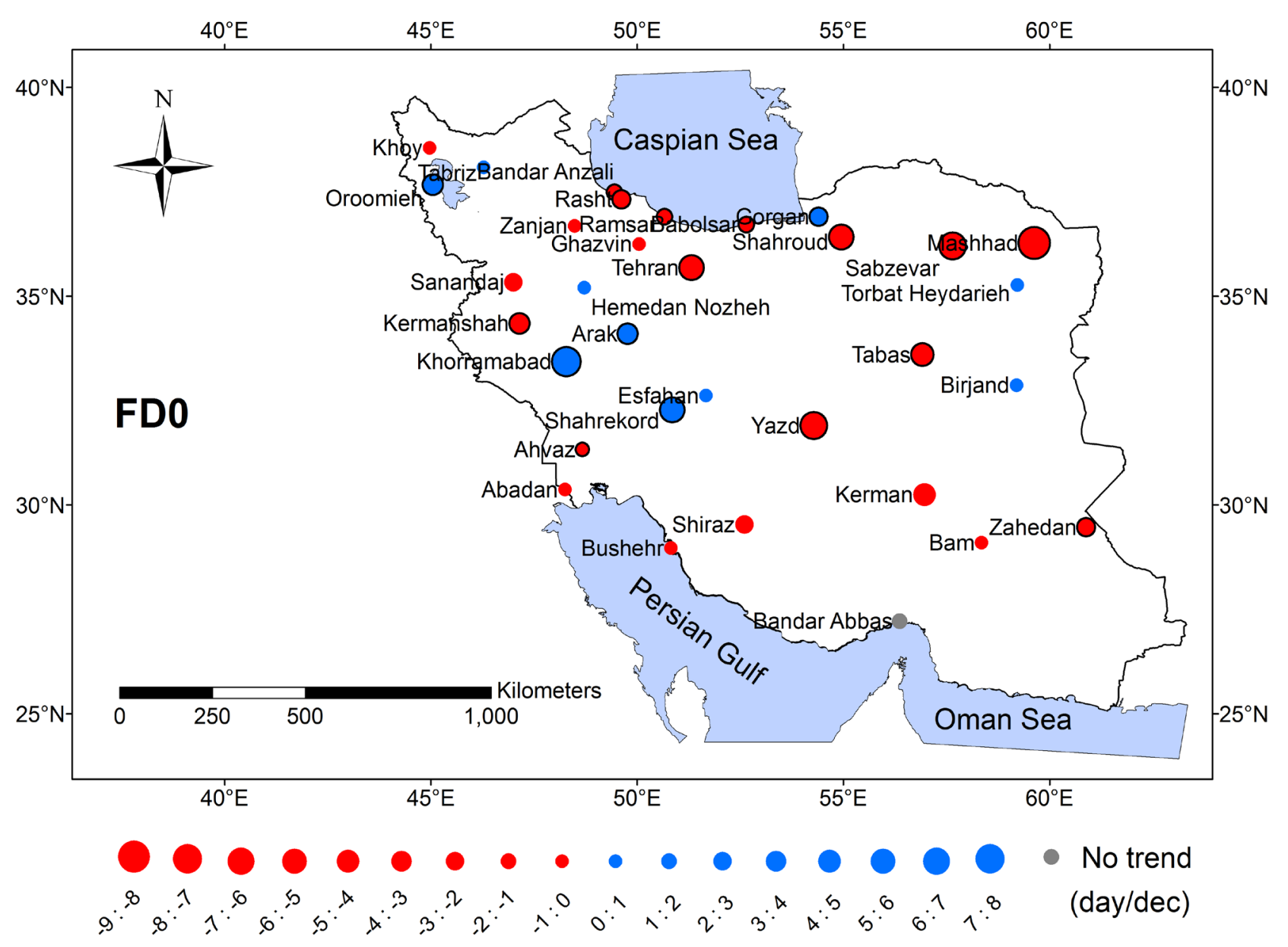

Figure 7. Decadal trends in frost days index for the 1960-2014 period over Iran. Circles that have a bold black perimeter are significant at $5 \%$ confidence level.

significant positive trends in stations of Tehran and Ahvaz. In most stations, the index PRCPTOT was negative, but also insignificant. Ahvaz and Tehran stations however showed significant positive trends for this index.

The index of "Extremely wet days" showed a significant and strong increasing trend in coastal areas such as Ramsar, Babolsar, Bandar Abbas etc. But it showed a decreasing trend in inland stations. The dispersion of stations with an increasing trend for R95 index is more than those for R99 index. But the magnitude of decreasing values is greater in this index. For the "Annual total wet-day precipitation" index, the results show a significant increasing trend for a number of stations around the Alborz and Zagros Mountains and a decreasing trend in the rest of the country. Also, Ahvaz and Tehran had the highest level of increase in this index. Overall, in precipitation indices, Ahvaz and Tehran stations had significant increasing trends (in CWD and CDD indices). The results showed that precipitation changes are more heterogeneous in terms of location than are the temperature changes. Still, most of the areas showed a significant increasing trend in extreme precipitation values, precipitation intensity and precipitation frequency, which agrees with the results of [4]. We found a significant spatial 


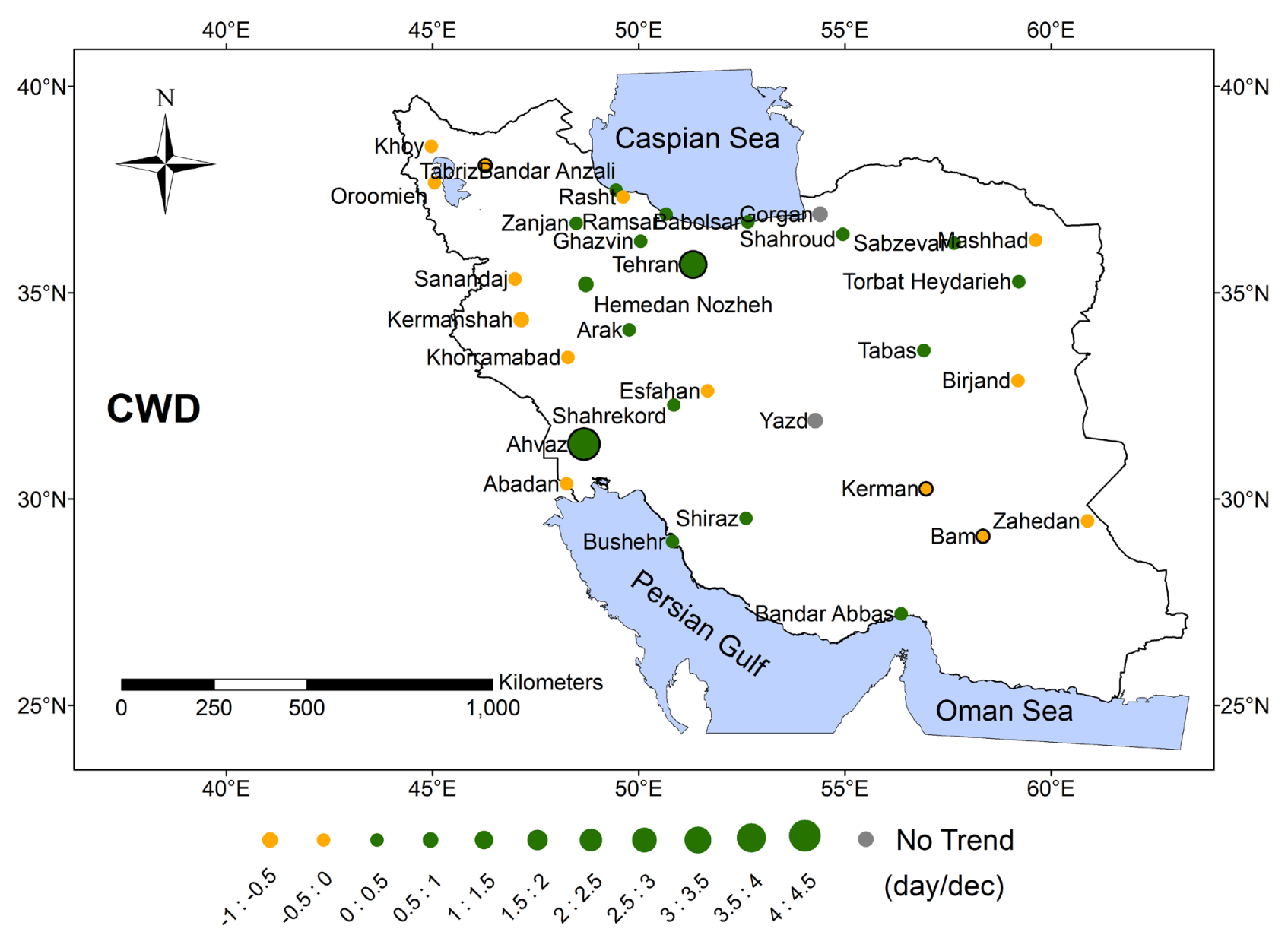

Figure 8. Decadal trends in CWD index for the 1960-2014 period over Iran. Circles that have a bold black perimeter are significant at $5 \%$ confidence level.

dependence in increasing trends of extreme temperature indices, as central regions of Iran showed sharper increasing trends than other regions. As for precipitation indices, significant positive trends were seen in southwestern regions of Iran and coasts of the Persian Gulf, same as [19]. Also, the results of this study are consistent with the results [19] in indicating the presence of a decreasing trend in extreme precipitation indices in northeastern parts of Iran. However, only a small number of trends observed for the studied period were significant.

\section{Conclusions}

Changes in frequency and intensity of extreme events can be more damaging than the changes in average climatic characteristics. Also, humans and ecosystems can react to changes in extreme climatic indices more severely than they do to changes in average indices. Therefore, analysis of trends in extreme climatic indices is important. In this study, we explored these trends in 33 selected stations in Iran. The extreme weather indices were calculated by the software RClimdex and trends were assessed by the Mann-Kendall method.

Generally the region is warming, although there is some spatial variability as 
the warming trend is mostly significant in northern and northeastern parts of the country. This study found a significant warming trend in the extreme temperature indices of many stations and our results support previous studies, including [3] [4] that have found that warming trend of minimum (nighttime) temperature extremes are stronger than maximum (daytime) temperature extremes. There is a warming trend in the intensity of extreme events (TXx, TNx, $\mathrm{TNn}$ ) with a positive trend in the temperature of the warmest maximum and minimum temperatures of the year and coolest minimum temperature. There are more significant trends in minimum temperature extremes, in line with other studies. In most stations, the index TNn exhibited a positive trend, and more significantly so for the northern half of the country. Trends in TNx were more spatially uniform. Out of 33 studied stations, 29 and 14 stations showed statically significant warming trends for, respectively, TNx and TNn, 21 and 25 stations showed statically significant warming trends for, respectively, TN10p and TN90p. There is a warming trend in the frequency of extreme events with more days above the 90th percentile and fewer days below the 10th percentile of maximum and minimum temperatures (TX90p, TN90p, TX10p, TN10p). TX90 was found to have a significant positive trend in most stations, but more significantly so in central and western parts of the country. Overall, changes in cool and warm days were found to be smaller than cool and warm nights frequency changes, which is in agreement with the findings of Donat et al. (2013). The duration of extreme events (WPDI, CSDI) also shows warming with most significant trends indicating longer warm spells and shorter cool spells. WSDI has had a significant positive trend over the entire country, except in Khorramabad and Torbat. The majority of significant trends in threshold based indices also indicate warming for the region. There are generally fewer FD with more SU and TR and a longer GSL. The weaker trends in TR20 were observed in northwest and some western parts of the country. Northern parts of the country however exhibited very strong and significant positive trend for the index.

There are fewer significant trends in precipitation, in line with previous studies [11]. Despite the lack of significance, most stations report increasing trends for SPII (Simple Daily Intensity Index) and RX1day (maximum 1-day precipitation). The sign of trends in CWD, R95p and RX5day are mixed. Overall, a majority of stations have reported negative trends for R10mm, R20mm, R25mm, CDD, R99p and PRCPTOT. The positive trend of CWD was found to be stronger than that of $\mathrm{CDD}$, and trends of $\mathrm{R} 25 \mathrm{~mm}$ were found to be weaker than those of R10mm and R20mm.

Global warming causes the evaporation to be increased in atmosphere and the water vapor capacity will be increased also according to Clausius-Clapeyron relation. Hence moderate and heavy precipitation which has more water vapor will be amplified. However these conditions occur in tropical regions which there are huge sources of humidity. According to our results the maxima indices of precipitation in Iran do not show significant increasing trend. This could be because 
of low precipitation of Iran plateau that most of the area is located in subtropical high pressure and the condition is not suitable for increasing water vapor in the atmosphere.

This study has made use of an extended record to calculate trends in extreme indices, compared to previous studies in Iran [8] [16]. However, one limitation may be that 55 years remains a short time to assess trends in regions with high interannual and decadal variability, particularly for variables such as precipitation that have a low signal to noise ratio. Further, we are limited to the use of 33 homogenous high-quality stations. Given the high spatial variability in the region this may not be enough to fully capture sub-regional trends.

In conclusion, the results show a decreasing trend in magnitude and frequency of extreme "cold" events and an increasing trend in magnitude and frequency of extreme "warm" events over the past 55 years, which support the results of IPCC and local studies reporting the warming trends of the climate. The relationship between the indices and ENSO is also suggested as future work.

\section{Acknowledgements}

The authors would like to thank the Iran National Science Foundation (INSF) for sponsoring this study.

\section{Conflicts of Interest}

The authors declare no conflicts of interest regarding the publication of this paper.

\section{References}

[1] IPCC (2007) Climate Change-The Scientific Basis. Intergovernmental Panel on Climate Change, Cambridge University Press, Cambridge.

[2] Frich, P., Alexander, L., Della-Marta, P., Gleason, B., Haylock, M., Klein Tank, A.M.G. and Peterson, T.C. (2002) Observed Coherent Changes in Climatic Extremes during the Second Half of the Twentieth Century. Climate Research, 19, 193-212. https://doi.org/10.3354/cr019193

[3] Alexander, L., Zhang, X., Peterson, T.C., Caesar, J., Gleason, B., Klein Tank, A.M.G., Haylock, M., Stephenson, D., BurnAguilar, J.E., Brunet, M., Taylor, M., New, M., Zhai, P., Rusticucci, M. and Azquez-Aguirre, J.L. (2006) Global Observed Changes in Daily Climate Extremes of Temperature and Precipitation. Journal of Geophysical Research, 111, D05109. https://doi.org/10.1029/2005JD006290

[4] Donat, M., Alexander, L., Yang, H., Durre, I., Vose, R., Dunn, R., Willett, K., Aguilar, E., Brunet, M. and Caesar, J. (2013) Updated Analyses of Temperature and Precipitation Extreme Indices since the Beginning of the Twentieth Century: The HadEX2 Dataset. Journal of Geophysical Research: Atmospheres, 118, 2098-2118. https://doi.org/10.1002/jgrd.50150

[5] Wang, L., Yao, Z.J., Jiang, L., Wang, R., Wu, S.S. and Liu, Z.F. (2016) Change in Climate Extremes and Catastrophic Events in the Mongolian Plateau from 1951 to 2012. Journal of Applied Meteorology and Climatology, 55, 1169-1182. https://doi.org/10.1175/JAMC-D-14-0282.1

[6] Yilmaz, A.G. (2014) The Effects of Climate Change on Historical and Future Ex- 
treme Rainfall in Antalya, Turkey. Hydrological Sciences Journal, 60, 2148-2162. https://doi.org/10.1080/02626667.2014.945455

[7] Mónica, S. and Santos, F. (2011) Trends in Extreme Daily Precipitation Indices in Northern of Portugal. Geophysical Research Abstracts, 14, EGU2012-8292.

[8] Whan, K., Alexander, L.V., Imielska, A., McGree, S., Jones, D., Ene, E. and Vaiimene, M. (2013) Trends and Variability of Temperature Extremes in the Tropical Western Pacific. International journal of Climatology, 34, 2585-2603. https://doi.org/10.1002/joc.3861

[9] Shahid, S. (2011) Trends in Extreme Rainfall Events of Bangladesh. Theoretical Applied Climatology, 104, 489-499. https://doi.org/10.1007/s00704-010-0363-y

[10] Mondal, A., Kundu, S. and Mukhopadhyay, A. (2012) Rainfall Trend Analysis by Mann-Kendal Test: A Case Study of North-Eastern Part of Cuttack District, Orassia. International Journal of Geology, Earth and Environmental Sciences, 2, 70-78.

[11] Rezaei, A., Mortazavi, M. and Rahimi, M. (2014) The Trend of Temperature Extreme Indices (ETCCDI) in Some Climate Sample for 1957-2008 Period. The 2nd Agricultural Meteorology National Conference, Karaj, May 2014, 76-86. (In Farsi)

[12] JahadiToroghi, M. (2000) Variation of Temperature and Precipitation of Mashhad during 1951-1994. Iranian Quarterly Geographical Research Journal, 54, 151-165. (In Farsi)

[13] Rahimi, M. and Hejabi, S. ( 2018) Spatial and Temporal Analysis of Trends in Extreme Temperature Indices in Iran over the Period 1960-2014. International Journal of Climatology, 38, 272-282. https://doi.org/10.1002/joc.5175

[14] Rasooli, A. (2002) Analysis of Time Series of Tabriz Air Temperature. Iranian Nivar Journal, 46, 7-26. (In Farsi)

[15] Rahimzadeh, F. and Asgari, A. (2003) A Survey on Recent Climate Change over IRAN. Proceeding of 14 th Global Warming International Conference \& Expo, Boston, May 2003, 27-30.

[16] Rahimzadeh, F. and Asgari, A. (2005) A Look at Difference of Increase Rates of Minimum with Maximum Temperature and at Decrease Rates of Diurnal Temperature Range (DTR) in Iran. Iranian Quarterly Geographical Research Journal, 73, 153-171. (In Farsi)

[17] Pedram, M., Rahimzadeh, F., Sahraian, F. and Noohi, K. (2005) Change in the Frost Free Season Length and Number of Frost Days in the West and East Azerbaijan Provinces. 1st International Conference on Climate Change and the Middle East. Past, Present and Future, Istanbul, July 2005, 20-23.

[18] Parak, F., Roshani, A. and BodaghJamali, J. (2015) Trend and Anomalies in Daily Climate Extremes over Iran during 1961-2010. Journal of Environmental and Agricultural Sciences, 2, 11-28.

[19] Kouzegaran, S. and MousaviBaygi, M. (2015) Investigation of Meteorological Extreme Event in the North-East of Iran. Journal of Water and Soil, 29, 750-764.

[20] Rahimi, M. (2012) Analyzing the Temporal and Spatial Variation of Fog Days in Iran. Pure and Applied Geophysics, 169, 1165-1172. https://doi.org/10.1007/s00024-011-0326-y

[21] Rahimi, M. and Eccel, E. (2013) Modelling the Effects of Meteorological and Geographical Drivers on Damage from Late Radiation Frost on Apple Trees in Northeast Iran. Italian Journal of Agrometeorology, 3, 13-22.

[22] Alijani, B. (1997) Temporal Changes of Tehran Temperature. Conference Proceedings of 1 st Regional on Climate Change, Tehran, May 1997, 22-24. (In Farsi) 